\section{BMJ Open \\ Respiratory \\ Research}

\title{
Timing of hypertonic saline and airway clearance techniques in adults with cystic fibrosis during pulmonary exacerbation: pilot data from a randomised crossover study
}

Katherine O'Neill, ${ }^{1}$ Fidelma Moran, ${ }^{2}$ Michael M Tunney, ${ }^{3} \mathrm{~J}$ Stuart Elborn, ${ }^{1}$ Ian Bradbury, ${ }^{4}$ Damian G Downey, ${ }^{5}$ Jackie Rendall, ${ }^{5}$ Judy M Bradley ${ }^{6}$

\section{ABSTRACT}

Background: Streamlining the timing of treatments in cystic fibrosis (CF) is important to optimise adherence while ensuring efficacy. The optimal timing of treatment with hypertonic saline (HTS) and airway clearance techniques (ACT) is unknown.

Objectives: This study hypothesised that HTS before ACT would be more effective than HTS during ACT as measured by Lung Clearance Index $(\mathrm{LCl})$.

Methods: Adults with CF providing written informed consent were randomised to a crossover trial of HTS before ACT or HTS during ACT on consecutive days. ACT treatment consisted of Acapella Duet. Patients completed $\mathrm{LCl}$ and spirometry at baseline and $90 \mathrm{~min}$ post treatment. Mean difference (MD) and 95\% Cls were reported.

Results: 13 subjects completed the study (mean (SD) age 33 (12) years, forced expiratory volume in 1second $\%\left(\mathrm{FEV}_{1} \%\right.$ ) predicted $51 \%$ (22), LCl (no. turnovers) 14 (4)). Comparing the two treatments (HTS before ACT vs HTS during ACT), the change from baseline to 90 min post treatment in $\mathrm{LCl}(\mathrm{MD}(95 \% \mathrm{Cl})-0.02$ $(-0.63$ to 0.59$))$ and $\mathrm{FEV}_{1} \%$ predicted $(\mathrm{MD}(95 \% \mathrm{Cl})$ $-0.25(-2.50$ to 1.99$))$ was not significant. There was no difference in sputum weight ( $\mathrm{MD}(95 \% \mathrm{Cl})-3.0$ $(-14.9$ to 8.9$))$, patient perceived ease of clearance (MD $(95 \% \mathrm{Cl}) 0.4(-0.6$ to 1.3$)$ or satisfaction (MD $(95 \% \mathrm{Cl}) 0.4(-0.6$ to 1.5$))$. The time taken for HTS during ACT was significantly shorter (MD $(95 \% \mathrm{Cl})$ 14.7 (9.8 to 19.6)).

Conclusions: In this pilot study, HTS before ACT was no more effective than HTS during ACT as measured by LCl.

Trial registration number: NCT01753869;

Pre-results.
For numbered affiliations see end of article.

\section{Correspondence to} Dr Katherine O'Neill; k.oneill@qub.ac.uk

\section{INTRODUCTION}

There is clear evidence that airway clearance techniques (ACT) to improve mucus clearance should form part of treatment in cystic

\section{KEY MESSAGES}

Optimal timing of treatment with hypertonic saline (HTS) and airway clearance techniques (ACT) is unknown.

- In this pilot study, HTS before ACT was no more effective than HTS during ACT as measured by Lung Clearance Index (LCI).

- LCI may not be a suitable short-term end point for airways clearance trials as response is unpredictable.

fibrosis $(\mathrm{CF})^{1-4}$ and emerging evidence that some forms of ACT may be more effective in the long term. ${ }^{5}$ Quality of evidence in this area is variable highlighting the need for high-quality trials in the future to provide a more robust evidence base for treatment. Often, technique choice remains dependent on patient preference and convenience as well as age and stage of disease. ${ }^{5-7}$ Recent research strategy has shifted from examining the comparative efficacy of different ACT to the study of ways to optimise the application of techniques. ${ }^{6}$ Finding the optimal treatment for a patient at any specific time requires consideration of available research evidence on efficacy among a range of other factors including coordination with inhaled therapies. ${ }^{8}$ Some forms of ACT now offer the possibility to deliver inhaled therapies during treatment and while these devices are attractive in terms of reducing the time burden associated with treatment, it is unclear how the timing of inhaled therapies impact on the effectiveness of ACT. Mucoactive agents such as hypertonic saline (HTS) are recommended to facilitate mucociliary clearance based on clear evidence from high-quality clinical trials across the age range and 
disease trajectory in $\mathrm{CF}^{9-14}$ These trials typically administered HTS before ACT and this is currently the clinical recommendation. Notably, some technologies to deliver HTS during ACT were not available when these trials were conducted and further studies of these methods may yield useful results.

A recent Cochrane review highlighted how clinical effect could be influenced by the timing of HTS delivery in relation to ACT. The review outlined a number of potential theoretical benefits to inhalation of HTS during airway clearance, including maximising the benefits of the immediate peak in the airway surface liquid volume and reduced treatment time. ${ }^{15}$ Following this review, a randomised controlled trial of 50 adult patients with $\mathrm{CF}$ assessed the change in lung function (forced expiratory volume in 1 second $\%\left(\mathrm{FEV}_{1} \%\right)$ predicted) and perceived effectiveness and satisfaction of three treatment regimens (HTS before, during and after ACT) at the end of a hospital admission. ${ }^{16}$ This study found that effects on $\mathrm{FEV}_{1}$ were not significant. Satisfaction was rated significantly worse when HTS was inhaled after ACT compared with before or during ACT. Perceived effectiveness of treatment showed similar effects. The study concluded that people with CF should be encouraged to time HTS before or during ACT to maximise perceived efficacy and satisfaction. There are currently no data on the effect of HTS and ACT timing on the Lung Clearance Index (LCI). LCI provides an assessment of ventilation distribution as measured by multiple-breath washout (MBW) which is increasingly being used in CF interventional studies. ${ }^{17}$ It is established that $\mathrm{FEV}_{1}$ lacks sufficient sensitivity to detect changes in the peripheral airways. ${ }^{18}$ LCI has shown greater sensitivity to abnormalities in lung function compared with spirometry across the age ranges in $\mathrm{CF}^{19} 20$ and has proven responsiveness in trials of inhaled therapies $^{21}{ }^{22}$ and $\mathrm{ACT}^{23}$ in CF. Importantly, significant improvements in LCI have been reported with relatively small numbers of patients $(\mathrm{n}=17-25) .{ }^{14} 212224$ These studies support the exploration of the effects of ACT in CF using LCI.

This pilot study aimed to compare the change in LCI at 90 min post treatment with HTS inhalation before ACT compared with HTS inhalation during ACT in adult patients with CF. Secondary outcomes included the change in $\mathrm{FEV}_{1} \%$ predicted, forced expiratory flow $(\mathrm{FEF})_{25-75} \%$ predicted, 24-hour sputum volumes, patient-perceived and physiotherapist-perceived ease of clearance and satisfaction with treatment, number of coughs and duration of treatment.

\section{METHOD}

\section{Subject recruitment}

Inclusion criteria for the study were subjects with $\mathrm{CF}$ aged $\geq 18$ years, near the end of an intravenous antibiotic (IVAB) therapy course (days 10-14) for a pulmonary exacerbation at Belfast Health and Social Care Trust
(BHSCT), who were productive of sputum $\geq 10$ g over 24 hours on enrolment, currently use or had previously used and tolerated HTS (Nebusal 7\%) and provided written informed consent. The exclusion criteria were subjects who are HTS naive, had a reported intolerance to HTS, currently participating in another study or have participated in another study with an investigational drug within 1 month of screening, or had a clinically significant condition other than CF or CF-related conditions that could compromise the safety of the patient or the quality of the data.

Subjects were recruited between December 2012 and January 2015. This study was approved by the Office for Research Ethics Committees Northern Ireland (REC reference number 12/NI/0153), sponsored by Belfast Health and Social Care Trust (reference number: 12025JB-AS) and registered with clinicaltrials.gov (reference number NCT01753869).

\section{Treatment}

Subjects were randomised to complete crossover treatment of HTS before ACT inhalation (treatment order A) and HTS inhalation during ACT (treatment order B) on consecutive days. The ACT chosen was the Acapella (Acapella Duet Vibratory PEP Therapy System, Portex, Smiths Medical) which allowed for HTS inhalation during treatment. Both subjects who were Acapella naive and subjects who had previous experience of using Acapella were included. Randomisation was electronically generated and concealed by an administrator independent of the study. Treatment was assigned and carried out by a qualified respiratory physiotherapist (FM, JMB, KMcD). Full details for each treatment order are presented in table 1 . The assessor conducting the outcome measures $\left(\mathrm{KO}^{\prime} \mathrm{N}\right)$ was blinded to the treatment intervention order.

\section{OUTCOME MEASURES}

\section{Lung Clearance Index}

The MBW test to measure LCI was carried out using the modified Innocor device and $0.2 \%$ sulfur hexafluoride $\left(\mathrm{SF}_{6}\right)$ using the previously validated open-circuit technique in accordance with the standard operating procedure (see online supplement 2).$^{25}$ Subjects breathed through a mouthpiece at normal tidal volumes, while in a seated position and wearing a nose clip. Analysis of MBW data was performed using the Simple Washout Programme (permission granted). Functional residual capacity (FRC) was calculated as part of the LCI equation $(\mathrm{LCI}=$ cumulative expired volume/FRC). LCI represents the number of FRC lung volume turnovers it takes to clear the inert gas $\left(\mathrm{SF}_{6}\right)$ from the lungs and quantifies the degree of uneven gas mixing throughout the lungs. MBW was performed before, immediately after and $90 \mathrm{~min}$ after the treatment intervention. Ninety minutes was considered the longest period that was reasonable for a subject to wait. MBW was carried out 


\section{Table 1 Treatment order details}

\begin{tabular}{ll}
\hline Treatment order & Detail \\
\hline Treatment order A: & Bronchodilator (Salbutamol \\
HTS before ACT & $200 \mathrm{mcg}$ ); \\
& Wait $15 \mathrm{~min} ;$ \\
& Single inhalation (4 mL) of $7 \%$ \\
& HTS (Nebusal) via updraft \\
& nebuliser (Portex) $(\sim 20 \mathrm{~min}) ;$ \\
& Immediately followed by an \\
& airways clearance session of 10 \\
& supervised cycles using the \\
& Acapella and forced expiration \\
& techniques ( 20 min). \\
Treatment order B: & Bronchodilator (Salbutamol \\
& 200 mcg); \\
HTS during ACT & Wait 15 min; \\
& Single inhalation (4 mL) of 7\% \\
& HTS (Nebusal) through the \\
& Acapella Duet (with Portex updraft \\
& nebuliser attached) device; \\
& During inhalation, an airways \\
& clearance session of 10 \\
& supervised cycles using the \\
& Acapella and forced expiration \\
& techniques was carried out \\
& ( 20 min). \\
\hline
\end{tabular}

Detailed content of the supervised cycles using the Acapella is provided in online supplement 1 . Subjects received the treatments at the same time each day, in the same position (high sitting) and the treatment duration was recorded.

ACT, airway clearance treatment; HTS, hypertonic saline.

either before or at least 30 min after spirometry in order to avoid any effects of forced breathing manoeuvre on LCI.

\section{Spirometry}

Spirometry was measured according to American Thoracic Society/European Respiratory Society (ATS)/ (ERS) guidelines ${ }^{26}$ using a Microlab (ML3500 MK8) spirometer (CareFusion, Kent, UK). $\mathrm{FEV}_{1} \%$ predicted and $\mathrm{FEF}_{35-75} \%$ predicted values were calculated from reference ranges for all ages. ${ }^{27}$

\section{Sputum wet weight}

Wet-weight sputum (g) expectorated immediately after each treatment session and total wet-weight sputum expectorated in the 24 hours following the start of each study visit was collected in preweighed containers and recorded (Metter J Balance, Meter-Toledo, Switzerland).

\section{Patient-perceived and physiotherapist-perceived ease of clearance and satisfaction}

Subjects and the physiotherapist delivering the treatment intervention scored their perceived ease of sputum clearance and level of satisfaction with each treatment using a Visual Analogue Scale labelled not easy/not satisfied and extremely easy/extremely satisfied) (see online supplement 3).

\section{Cough count}

During each treatment session, the physiotherapist performed a manual 'cough count' recording the number of coughs per treatment session.

\section{Statistical analysis}

For the primary end point of change in LCI at $90 \mathrm{~min}$ post treatment, a sample size of $n=31$ was estimated to detect a treatment effect size of 1.5 assuming a significance level of $5 \%$ and a power of $80 \%$. An interim analysis was planned at the halfway point. Data were summarised using mean (SD) or median (IQR) statistics as appropriate. Wilcoxon test and McNemar's test were used to assess change in the variables of interest. Mean difference (MD) and 95\% CIs were reported. Treatment effect size was calculated as $\mathrm{z}$ /square root of $\mathrm{N}$ (number of observations). Correlations were assessed using the Spearman's rho correlation coefficient. A $p$ value $<0.05$ was considered statistically significant.

\section{RESULTS}

Following an interim analysis to compare change in LCI at $1 \% \alpha$ in data from 13 subjects, results showed the treatment effect was unlikely to be sufficiently large to attain clinical or statistical significance. Given this and challenges with recruitment, the decision was made to terminate the study at this point. These study results are presented as pilot data to inform future studies.

Fourteen subjects were recruited and 13 completed the study. Figure 1 illustrates the flow chart of recruitment. Table 2 presents subject baseline characteristics.

\section{Within-treatment change}

The change in LCI from baseline to $90 \mathrm{~min}$ post treatment with HTS before ACT (MD (95\% CI) $0.10 \quad(-0.59$ to $0.79)$ ) or with HTS during ACT (MD (95\% CI) 0.12 $(-0.42$ to 0.66$)$ ) was not significant (table 3 and figure $2 \mathrm{~A}$, B). The FRC (component of the LCI) was significantly reduced with HTS during ACT treatment (MD (95\% CI) -0.11 ( 0.20 to 0.03$)$ ), but was unchanged with HTS before ACT treatment (MD (95\% CI) $-0.55(-0.17$ to 0.06$)$ ). With ACT after HTS, 8/13 patients worsened (ie, LCI increased) and 5/13 patients improved (ie, LCI decreased). With HTS during ACT, 7/13 worsened (ie, LCI increased) and 6/13 improved (ie, LCI decreased). Change in LCI from baseline to immediately after treatment with HTS before ACT (MD $(95 \%$ CI $)-0.10(-0.49$ to 0.27$)$ ) or with HTS during ACT (MD (95\% CI) 0.08 $(-0.69$ to 0.84$)$ ) was also not significant (data not shown).

Considering the secondary outcome measures, the change in $\mathrm{FEV}_{1} \%$ predicted (after $90 \mathrm{~min}$ ) with HTS before ACT was not significant (MD (95\% CI) 1.38 (-0.61 to 3.38) ) 10/13 improved (ie, $\mathrm{FEV}_{1}$ increased), 2/13 worsened (ie, $\mathrm{FEV}_{1}$ decreased) and 1/13 stayed the same. There was also no significant change with HTS during ACT (MD (95\% CI) 1.64 (-1.06 to 4.34)); 7/13 patients improved (ie, $\mathrm{FEV}_{1}$ increased), 4/13 


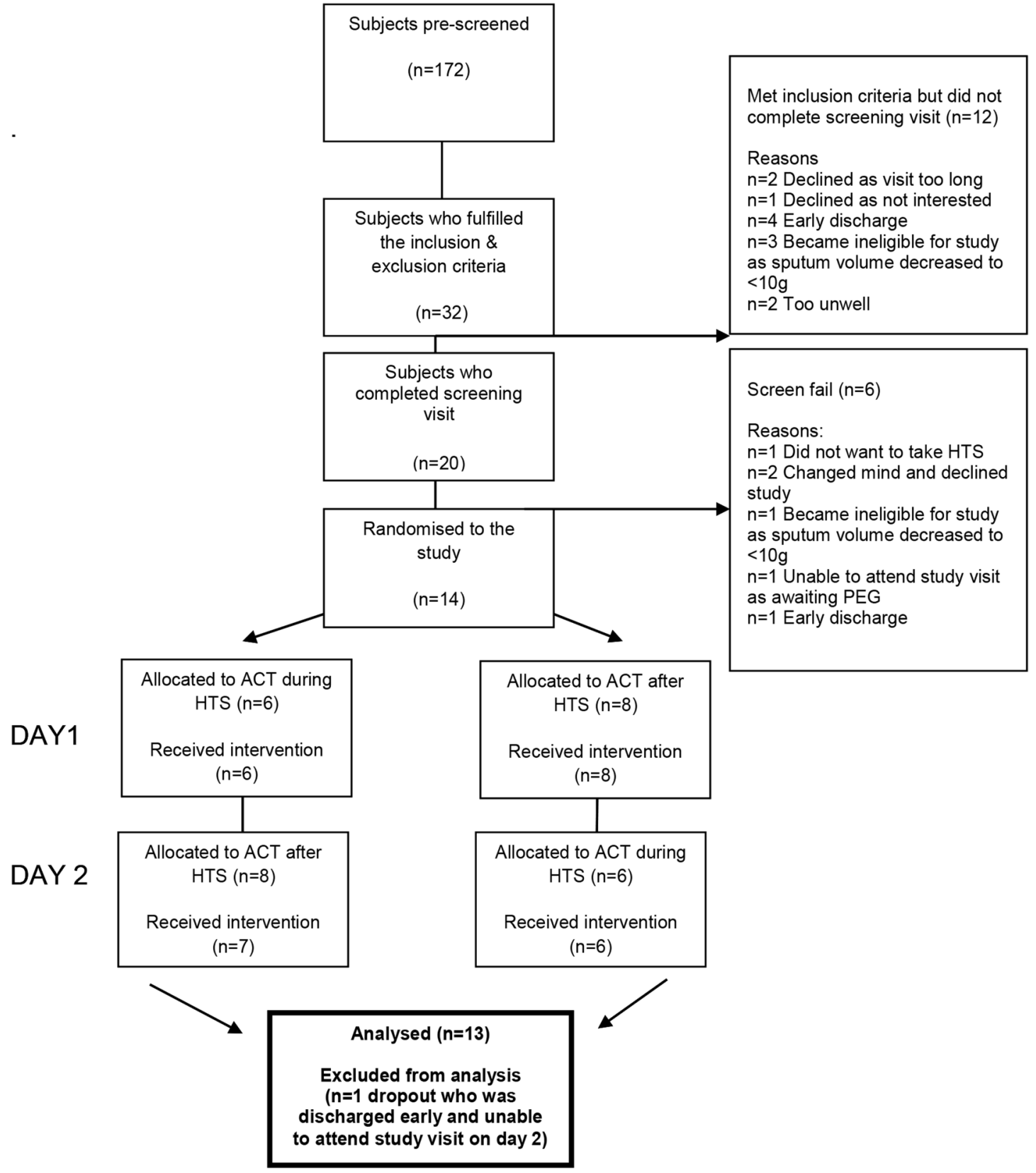

Figure 1 Flow chart of recruitment.

worsened (ie, $\mathrm{FEV}_{1}$ decreased) and 2/13 stayed the same (table 3 and e-figure $1 \mathrm{~b}$ ). There was also no significant change in $\mathrm{FEF}_{35-75} \%$ predicted with either treatment (table 3 and e-figures $2 \mathrm{a}$ and $\mathrm{b}$ ).

\section{Between-treatment change}

Comparing the two treatments (HTS before ACT vs HTS during ACT), the change from baseline to immediately post treatment in LCI (MD (95\% CI) $-0.05(-1.10$ to 1.00)) and the change from baseline to $90 \mathrm{~min}$ post treatment in LCI (MD (95\% CI) -0.02 ( -0.63 to 0.59$)$ ), $\mathrm{FEV}_{1} \%$ predicted (MD $(95 \% \mathrm{CI})-0.25(-2.50$ to 1.99$)$ ) and $\mathrm{FEF}_{35-75} \%$ predicted (MD (95\% CI) -1.92 (-6.28 to 2.43)) was not significantly different.
With both treatment orders, the change in LCI and change in $\mathrm{FEV}_{1} \%$ predicted at 90 min post treatment was not always in agreement. With HTS before ACT, LCI and $\mathrm{FEV}_{1} \%$ predicted results were in agreement in $7 / 13$ subjects $(54 \%) \quad(\mathrm{r}=-0.51 ; \mathrm{p}=0.08)$. With HTS during ACT, LCI and $\mathrm{FEV}_{1}$ results were in agreement in 10/13 $(77 \%)$ subjects $(\mathrm{r}=-0.48 ; \mathrm{p}=0.10)$.

Comparing the two treatments (HTS before ACT vs HTS during ACT) using the other study end points, there was no difference in sputum weight expectorated immediately post (MD (95\% CI) $-3.0(-14.9$ to 8.9$))$ or 24 hours post treatment (MD $(95 \%$ CI $) 77.4$ (86.1 to 241.0)), patient-perceived ease of clearance (MD (95\% CI) 0.4 (-0.6 to 1.3$)$ ) or satisfaction (MD (95\% CI) 0.4 $(-0.6$ to 1.5$))$. There was also no difference in the 
Table 2 Subject baseline characteristics $(n=13)$

\section{Baseline characteristics}

Age (years)

Female/male

$33.2(12.2)$

Median (IQR) 24-hour sputum weight (g)

5:8

$\mathrm{FEV}_{1} \%$ predicted

Median (IQR) $\mathrm{FEF}_{25-75} \%$ predicted

LCI (no. turnovers)

Mean (SD) unless otherwise stated.

$\mathrm{FEF}_{25-75} \%$ predicted, forced expiratory flow 25-75; $\mathrm{FEV}_{1}$ predicted, forced expiratory volume in $1 \mathrm{~s}$; LCI, Lung Clearance Index.
$20.0(25.0)$

$51.1(22.0)$

$14.0(38.0)$

$13.9(3.7)$

physiotherapist perception of the ease of clearance (MD (95\% CI) 0.7 ( -0.2 to 1.6)), physiotherapist perception of the satisfaction with treatment (MD $(95 \%$ CI) -0.4 $(-0.6$ to 1.3$))$ or in the number of coughs recorded between treatments (MD (95\% CI) 6.2 (-0.02 to 12.5)). The time taken for HTS during ACT was significantly shorter (MD (95\% CI) 14.7 (9.8 to 19.6)) (e-table 1).

\section{DISCUSSION AND CONCLUSIONS}

As technology advances, more efficient ways of delivering inhaled therapies linked to ACT are being explored in an effort to reduce the treatment time required. This pilot study aimed to explore the effectiveness of one such strategy, HTS during ACT using the Acapella Duet.

This pilot study found that the timing of HTS in relation to ACT did not have a significant effect on the change in LCI after a single treatment session. Although HTS during ACT was significantly shorter in duration, secondary end points of spirometry, sputum volumes, patient and physiotherapist perception of ease and satisfaction, and number of coughs were also not significantly different between treatments.

These results are in agreement with the findings by Dentice and colleagues, ${ }^{16}$ who found no difference in lung function between regimens (HTS before, during or after ACT) and reported similar numbers of patients stating a preference for ACT after or during HTS, compared with ACT before HTS. The authors concluded that preference for HTS before or during ACT over HTS after ACT, could have implications for long-term adherence. The pilot data presented in this paper adds to this topic further exploring differences between HTS before or during ACT regimens. Results suggest that if length of treatment time is an issue affecting adherence, HTS during ACT may offer a regimen which is equally effective but of shorter duration. Furthermore, although not statistically significant, notably fewer coughs were required to expectorate the same volume of sputum with ACT during HTS treatment compared with the HTS before ACT treatment.

Importantly, these results indicate that as a novel end point, LCI did not offer any further information in response to ACT and HTS treatment compared with spirometry. $\mathrm{FEV}_{1}$ is not always a suitable outcome measure

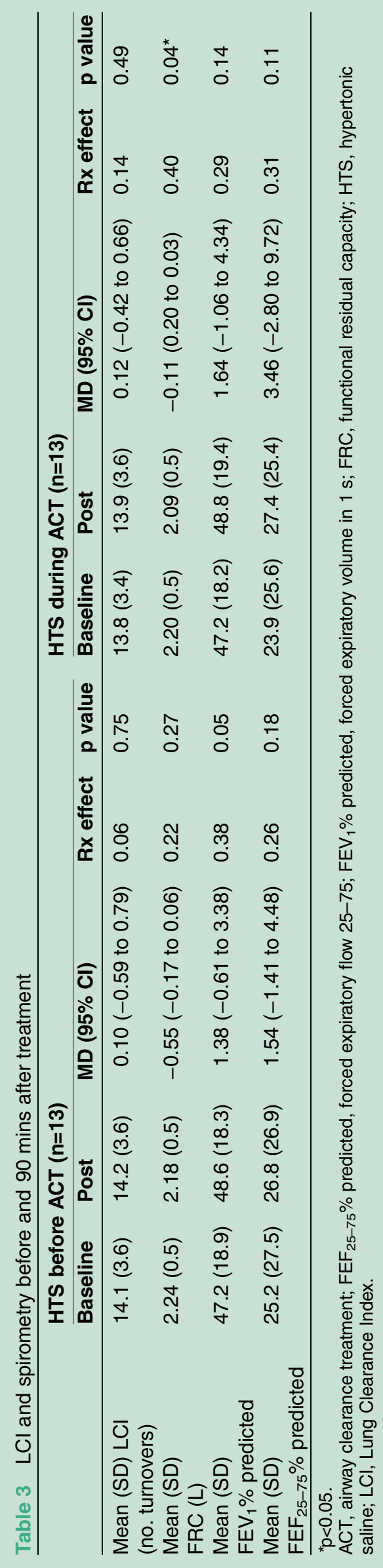


A

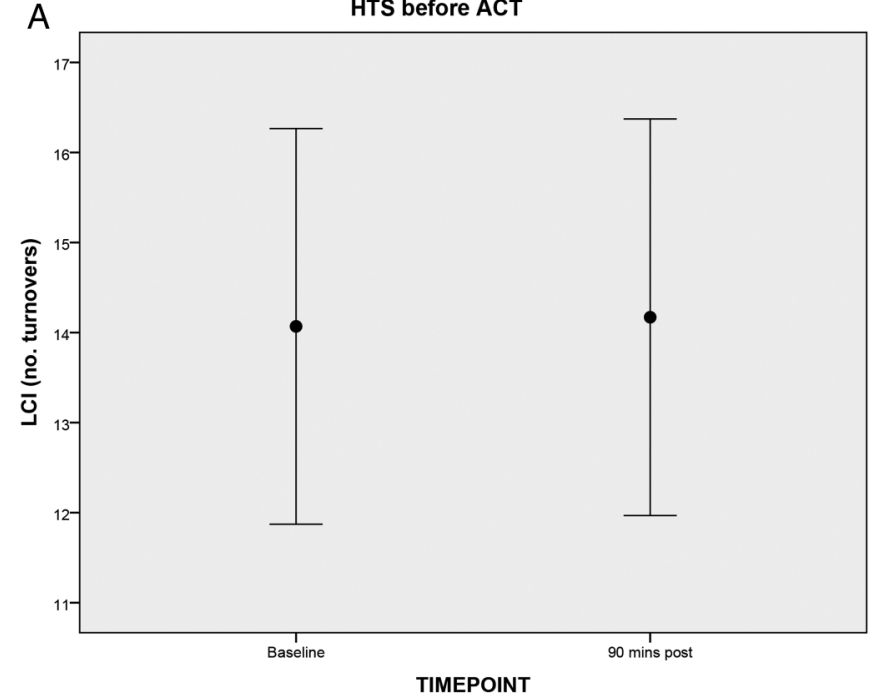

B
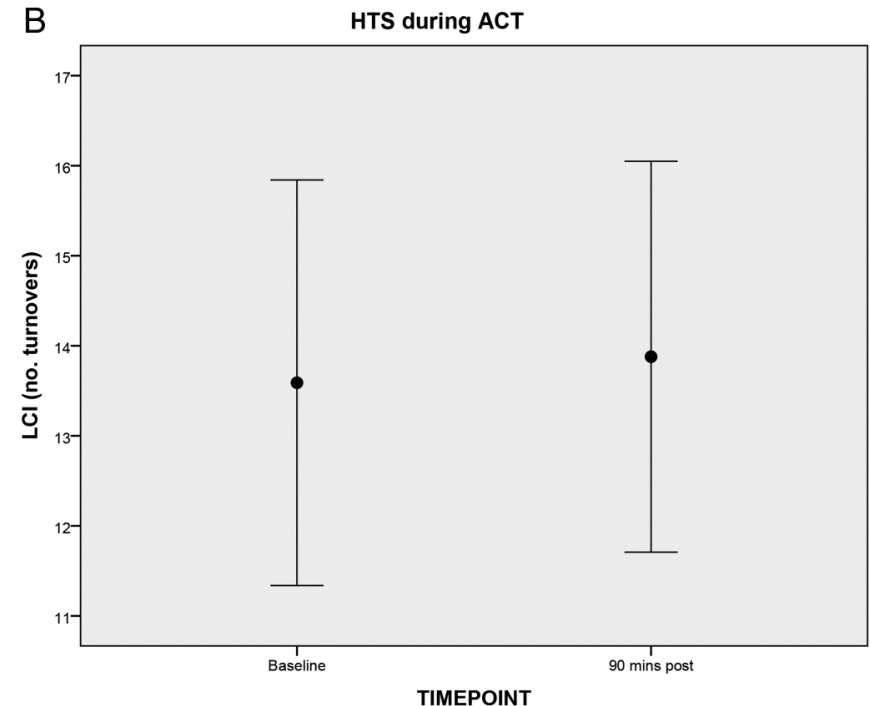

Figure 2 Change in LCl with (A) HTS before ACT and (B) HTS during ACT (mean and 95\% Cls). ACT, airway clearance treatment; HTS, hypertonic saline; LCl, Lung Clearance Index.

for ACT trials due to its lack of sensitivity as an end point. ${ }^{28}$ LCI was chosen as the primary outcome measure in this study as it has demonstrated superior sensitivity to changes in disease compared with spirometry ${ }^{20}$ and has proven responsiveness to treatment effect with inhaled therapies $^{142122}$ and $\mathrm{ACT}^{23}$ in CF. However, in this study, LCI did not detect any change within or between treatments. Change in LCI also did not significantly correlate with $\mathrm{FEV}_{1}$, with either treatment. Studies by Fuchs and colleagues $^{29}$ and Pfleger and colleagues ${ }^{30}$ have also reported small and inconsistent changes (increasing and decreasing) in LCI after physiotherapy with weak to modest correlations between change in LCI and $\mathrm{FEV}_{1}$. Results from this pilot study of patients primarily with moderate to severe lung disease, add to this data providing results from two time points (immediately post and 90 min post treatment) from a clearly defined intervention (inhaled therapy and ACT). The change in FRC as a component of LCI with HTS during ACT treatment was significantly decreased, but this did not translate to a change in LCI. These results suggest that the effects of sputum clearance on LCI and FRC are complex, as ACT may open previously completely obstructed airways resulting in the recruitment of lung units paradoxically increasing LCI. LCI may also be much less informative in those with significant airflow obstruction ${ }^{31}{ }^{32}$ which made up a large proportion of patients in this study $\left(8 / 13 \mathrm{FEV}_{1}\right.$ $<50 \%$ predicted at baseline). Discordant results with LCI and $\mathrm{FEV}_{1}$ may not be surprising as they each measure a different aspect of lung physiology. These results add to the argument that LCI may not be a suitable short-term end point for airways clearance trials as response is unpredictable. Previous studies reporting significant effects assessed treatment effect were not short term but over a period 4-48 weeks with inhaled therapies ${ }^{14} 2122$ and 3 months with airways clearance therapy. ${ }^{23}$ Lack of overall change in LCI in this study was in agreement with other end points including spirometry, sputum weight and patient preference supporting the validity of these results. The mean change in $\mathrm{FEV}_{1}$ from baseline to 90 min post treatment (with HTS before ACT) could not be considered clinically significant.

Wet-weight sputum was chosen as a secondary outcome measure as it is feasible to perform. However, we acknowledge the inherent limitations of this measure as a clinical trial end point. Expectorated wet-weight sputum can include saliva, introducing error. An increase of decrease in sputum can be interpreted as an improvement, that is, an increase may mean improvement in clearance or a decrease may mean a resolution in infection. These issues limit the use of sputum as a reliable trial end point, although it remains an end point that is meaningful to patients.

In this study, inpatients receiving IVAB for treatment of a pulmonary exacerbation were the target group for recruitment. This was for feasibility reasons as the study design involved treatment on two consecutive days which would likely have been prohibitive for outpatients. Although our study design aimed to ensure participants were as close to their stable status as possible (days 1014 IVAB), our recruitment process demonstrated how some patients were still unwell at this time point (ie, two patients failed screening as they felt too unwell to proceed; figure 1) and we cannot completely rule out the effect of pulmonary exacerbation on the variability of lung function results. ${ }^{31}$ However, this study represents a 'real-life' evaluation of a treatment that is often carried out during hospital admission.

This study investigated the use of a less commonly used adjunct (Acapella Duet) through which to deliver HTS during ACT. Using this device, we did not observe any significant deposition of HTS directly in the device and the resistance levels achieved remained optimum (between 10 and $20 \mathrm{cmH}_{2} \mathrm{O}$ ) in both treatments. 
Limitations of this study include the small sample size and findings need to be reproduced in a larger sample, therefore the conclusions must be interpreted with caution. Recruitment was challenging due to inclusion criteria in the study which required that subjects had previously taken and tolerated HTS and be productive of $\geq 10 \mathrm{~g}$ of sputum at the end of IVAB treatment. Of the subjects who met the criteria, the majority progressed to screening $(20 / 32 ; 63 \%)$ and thereafter randomisation $(14 / 20 ; 70 \%)$. Opening the study to outpatients could have increased the number of potentially eligible patients; however, adherence to the study design (attendance on two consecutive days), we believe, would have been challenging.

This pilot study is the first study to assess the effect of HTS and ACT timing using LCI as an outcome measure and employed rigorous study design including blinded outcome measure assessor and a broad range of measures.

Overall, the results from this pilot study could not support the hypothesis that HTS before ACT was more effective than HTS during ACT as measured by LCI. Results indicate that HTS during ACT was no more effective than HTS before ACT, although it did result in a shorter treatment duration.

\author{
Author affiliations \\ ${ }^{1}$ Centre for Experimental Medicine, Queen's University Belfast, Belfast, UK \\ ${ }^{2}$ School of Health Sciences, Ulster University, Jordanstown, UK \\ ${ }^{3}$ School of Pharmacy, Queen's University Belfast, Belfast, UK \\ ${ }^{4}$ Frontier Science (Scotland) Ltd, Scotland, UK \\ ${ }^{5}$ Belfast Health and Social Care Trust, Belfast, UK \\ ${ }^{6}$ Clinical Research Facility, Queen's University Belfast, Belfast, UK
}

Acknowledgements We would like to thank the patients who participated in this study, physiotherapist Dr Kathryn McDowell for her assistance in delivering treatments, Dr Alex Horsley (University of Manchester) and Dr Nick Bell (Department of Respiratory Medicine, Bristol Royal Infirmary) for permission to use the modified Innocor device standard operating procedure and the Simple Washout Programme for the analysis of MBW data.

Contributors KO'N, FM, MMT, JSE and JMB conceived and designed research; KO'N, FM and JMB recruited patients, performed treatment, collected clinical data and performed the assessments; KO'N, FM, MMT, IB, JSE and JMB analysed data; DGD and JR provided intellectual contributions; KO'N, FM, JMB, MMT and JSE wrote the paper.

Funding This work was supported by Forest Laboratories Europe.

Competing interests None declared.

Ethics approval This study was approved by the Office for Research Ethics Committees Northern Ireland (REC reference number 12/NI/0153).

Provenance and peer review Not commissioned; externally peer reviewed.

Data sharing statement No additional data are available.

Open Access This is an Open Access article distributed in accordance with the Creative Commons Attribution Non Commercial (CC BY-NC 4.0) license, which permits others to distribute, remix, adapt, build upon this work noncommercially, and license their derivative works on different terms, provided the original work is properly cited and the use is non-commercial. See: http:// creativecommons.org/licenses/by-nc/4.0/

\section{REFERENCES}

1. Warnock L, Gates A. Chest physiotherapy compared to no chest physiotherapy for cystic fibrosis. Cochrane Database Syst Rev 2015 (12):CD001401.

2. Morrison L, Agnew J. Oscillating devices for airway clearance in people with cystic fibrosis. Cochrane Database Syst Rev 2014;(7): CD006842.

3. Main E, Prasad A, Schans C. Conventional chest physiotherapy compared to other airway clearance techniques for cystic fibrosis. Cochrane Database Syst Rev 2005;(1):CD002011.

4. van der Schans C, Prasad A, Main E. Chest physiotherapy compared to no chest physiotherapy for cystic fibrosis. Cochrane Database Syst Rev 2000;(2):CD001401.

5. Mcllwaine M, Button B, Dwan K. Positive expiratory pressure physiotherapy for airway clearance in people with cystic fibrosis. Cochrane Database Syst Rev 2015;(6):CD003147.

6. Main E, Grillo L, Rand S. Airway clearance strategies in cystic fibrosis and non-cystic fibrosis bronchiectasis. Semin Respir Crit Care Med 2015;36:251-66.

7. Bradley JM, Moran FM, Elborn JS. Evidence for physical therapies (airway clearance and physical training) in cystic fibrosis: an overview of five Cochrane systematic reviews. Respir Med 2006;100:191-201.

8. Rand S, Hill L, Prasad SA. Physiotherapy in cystic fibrosis: optimising techniques to improve outcomes. Paediatr Respir Rev 2013;14:263-9.

9. Amin R, Stanojevic S, Kane M, et al. A randomized controlled trial to evaluate the lung clearance index as an outcome measure for early phase studies in patients with cystic fibrosis. Respir Med 2016;112:59-64.

10. Dentice RL, Elkins MR, Middleton PG, et al. A randomised trial of hypertonic saline during hospitalisation for exacerbation of cystic fibrosis. Thorax 2016;71:141-7.

11. Wark $P$, McDonald VM. Nebulised hypertonic saline for cystic fibrosis. Cochrane Database Syst Rev 2009;(2):CD001506.

12. Elkins MR, Bye PT. Inhaled hypertonic saline as a therapy for cystic fibrosis. Curr Opin Pulm Med 2006;12:445-52.

13. Eng PA, Morton J, Douglass JA, et al. Short-term efficacy of ultrasonically nebulized hypertonic saline in cystic fibrosis. Pediatr Pulmonol 1996;21:77-83.

14. Subbarao $\mathrm{P}$, Stanojevic $\mathrm{S}$, Brown $\mathrm{M}$, et al. Lung clearance index as an outcome measure for clinical trials in young children with cystic fibrosis. A pilot study using inhaled hypertonic saline. Am J Respir Crit Care Med 2013;188:456-60.

15. Elkins M, Dentice R. Timing of hypertonic saline inhalation for cystic fibrosis. Cochrane Database Syst Rev 2012;(2):CD008816.

16. Dentice RL, Elkins MR, Bye PTP. Adults with cystic fibrosis prefer hypertonic saline before or during airway clearance techniques: a randomised crossover trial. J Physiother 2012;58:33-40.

17. Stanojevic S, Ratjen F. Physiologic endpoints for clinical studies for cystic fibrosis. J Cyst Fibros 2016;15:416-23.

18. Robinson PD, Goldman MD, Gustafsson PM. Inert gas washout: theoretical background and clinical utility in respiratory disease. Respiration 2009;78:339-55.

19. Aurora P, Bush A, Gustafsson P, et al. Multiple-breath washout as a marker of lung disease in preschool children with cystic fibrosis. Am J Respir Crit Care Med 2005;171:249-56.

20. O'Neill K, Tunney MM, Johnston E, et al. Lung clearance index in adults and children with cystic fibrosis. Chest 2016;150:1323-32.

21. Amin R, Subbarao $P$, Jabar A, et al. Hypertonic saline improves the $\mathrm{LCl}$ in paediatric patients with CF with normal lung function. Thorax 2010;65:379-83.

22. Amin R, Subbarao P, Lou W, et al. The effect of dornase alfa on ventilation inhomogeneity in patients with cystic fibrosis. Eur Respir $J$ 2011:37:806-12.

23. Rodriguez Hortal MC, Nygren-Bonnier M, Hielte L. Non-invasive ventilation as airway clearance technique in cystic fibrosis. Physiother Res Int 2016. doi: 10.1002/pri.1667. [Epub ahead of print 29 Feb 2016]

24. Davies J, Sheridan H, Bell N, et al. Assessment of clinical response to ivacaftor with lung clearance index in cystic fibrosis patients with a G551D-CFTR mutation and preserved spirometry: a randomised controlled trial. Lancet Respir Med 2013;1:630-8.

25. Horsley AR, Gustafsson PM, Macleod KA, et al. Lung clearance index is a sensitive, repeatable and practical measure of airways disease in adults with cystic fibrosis. Thorax 2008;63:135-40.

26. Miller MR, Hankinson J, Brusasco V, et al. Standardisation of spirometry. Eur Respir J 2005;26:319-38. 
27. Stanojevic S, Wade A, Stocks J, et al. Reference ranges for spirometry across all ages. Am J Respir Crit Care Med 2008;177:253-60.

28. Main $\mathrm{E}$. What is the best airway clearance technique in cystic fibrosis? Paediatr Respir Rev 2013;14(Suppl 1):10-12.

29. Fuchs SI, Toussaint S, Edlhaimb B, et al. Short-term effect of physiotherapy on variability of the lung clearance index in children with cystic fibrosis. Pediatr Pulmonol 2010;45:301-6.
30. Pfleger A, Steinbacher M, Schwantzer G, et al. Short-term effects of physiotherapy on ventilation inhomogeneity in cystic fibrosis patients with a wide range of lung disease severity. J Cyst Fibros 2015;14:627-31.

31. Sonneveld N, Stanojevic S, Amin R, et al. Lung clearance index in cystic fibrosis subjects treated for pulmonary exacerbations. Eur Respir J 2015;46:1055-64.

32. Horsley A. Lung clearance index in the assessment of airways disease. Respir Med 2009;103:793-9. 